\title{
Segmentacija trga in spremembe na področju nizkocenovnih hotelov na mestnih območjih Južnoafriške republike
}

Segmentacija trga močno vpliva na spremembe v hotelski dejavnosti, pri čemer se gradijo različne oblike hotelov, tudi nizkocenovni. Večina mednarodnih raziskav tovrstnih hotelov se osredotoča samo na Severno Ameriko in Evropo, nekaj novejših raziskav pa obravnava tudi gospodarstva v vzponu. Avtorica v članku preučuje vlogo nizkocenovnih hotelov v okviru širšega prestrukturiranja industrijske dejavnosti v Južnoafriški republiki, odkar se je ta po spremembi politične ureditve ponovno vključila $\mathrm{v}$ svetovno turistično gospodarstvo. $\mathrm{V}$ preteklosti so bili za južnoafriško hotelsko ponudbo značilni nizkocenovni hoteli z eno zvezdico ali dvema, kar je bila posledica državne zakonodaje o točenju alkohola. Po preoblikovanju hotelske dejavnosti po letu 1990, ki naj bi zadovoljila potrebe rastočega mednarodnega turističnega trga, se je vloga nizkocenovnih hotelov spremenila. Avtorica analizira zmanjšano vlogo teh hotelov v hotelski dejavnosti Južnoafriške republike, njihovo spremenljivo naravo in spremembe lokacije od leta 1990 do danes. Ugotavlja, da je večina nizkocenovnih hotelov, zgrajenih po letu 1990, zgoščena $\mathrm{v}$ velikih mestih in sekundarnih središčih $\mathrm{v} d r-$ žavi in da so nekdanje nizkocenovne hotele $\mathrm{v}$ manjših mestih, ki so služili predvsem s prodajo alkohola, nadomestile druge oblike nastanitve.

Ključne besede: segmentacija, hotelska dejavnost, nizkocenovni hoteli, Južnoafriška republika 


\section{Uvod}

Dallen Timothy in Victor Teye (2009) poudarjata, da se na področju nastanitvenih storitev največ raziskav osredotoča na vidik poslovnega upravljanja nastanitev oziroma na gostinski vidik. Čeprav je ta pristop pomemben, raziskovalci nastanitev zanemarjajo njihovo širšo vlogo v nacionalnem in svetovnem turističnem sistemu. Kot navajata Colin Michael Hall in Stephen Page (2006: 108), imajo turistične nastanitve $» v$ mestih pomembno funkcijo «. David Solnet idr. (2010) opozarjajo na pomembno vlogo hotelov $\mathrm{v}$ turističnih sistemih, Slavoj Medlik in Haydn Ingram (2000) pa poudarjata njihov pomen pri nudenju ustreznih prostorov za prostočasne in razvedrilne dejavnosti v mestih, poslovne dejavnosti ter organizacijo konferenc in sestankov. Kljub pomembni vlogi hotelov v mestih in turizmu je presenetljivo, da jih urbanisti in turistični strokovnjaki le redko preučujejo, zlasti v primerjavi z drugimi urbanimi dejavniki, kot je gradnja stanovanj, trgovin in pisarn (Shoval in Cohen-Hattab, 2001). Pri pregledu družboslovne literature o hotelih $\mathrm{v}$ mestih lahko ugotovimo, da jih preučujejo strokovnjaki z najrazličnejših področij (poslovne vede, humana geografija, ekonomija, sociologija in turizem). Pri tem obravnavajo različne teme, med drugim zgodovinski razvoj hotelov v mestih in njihovo vlogo $\mathrm{v}$ infrastrukturni dediščini mest (Teo, 2001; Teo in Chang, 2009, ter Azmy in Atef, 2011), prenovo in slabše poslovanje hotelov (Solnet idr., 2010), odnos med hoteli in urbanim prostorom, pri čemer so hoteli razpoznavni znak mesta ali vir ponosa prebivalcev (McNeill, 2008, ter McNeill in McNamara, 2009 in 2012), vpliv hotelov na postkomunistično preoblikovanje (Niewiadomski, 2009) in pomen načrtovanja hotelov in hotelskih prostorov (Rutes idr., 2001; McNeill, 2009, in Lee, 2011). Druge raziskave hotelov in mest se osredotočajo na njihovo lokacijo (Wall idr.,1985; Bégin, 2000; Urtasun in Gutiérrez, 2006, in Rogerson 2012a) ter vpliv segmentacije trga in pojava različnih oblik hotelov (Aggett, 2007, ter Rogerson in Kotze, 2011).

V članku se avtorica osredotoča na zadnji temi in preučuje doslej neraziskan vidik prestrukturiranja sodobne hotelske dejavnosti v Južnoafriški republiki, in sicer pojav in ureditev nizkocenovnih hotelov (ang. budget hotels). Po spremembi politične ureditve leta 1994 se je Južnoafriška republika ponovno vključila v sistem svetovnega turizma in doživela razcvet (Rogerson in Visser, 2004 in 2006). Južnoafriški turizem temelji predvsem na velikih mestih (Rogerson in Visser, 2007 in 2011a). Krepil se je od začetka 90. let 20. stoletja, zaradi česar so se močno preoblikovali glavni segmenti ponudbe turističnih storitev, tudi nastanitve v mestih. Vzporedno z razvojem hotelov drugje po svetu so bili v 90. letih 20. stoletja v državi uvedeni številni inovativni hotelski proizvodi, na primer letališki hoteli, hoteli s kuhinjo v vsaki sobi (ang. all-suite hotels), butični hoteli, hoteli z omejenimi storitvami in veliki razkošni hoteli (Rogerson, 2010; Rogerson in Kotze, 2011; Rogerson, 2011a in 2011b; Rogerson, 2012b; Ferreira in Boshoff, v tisku, ter Rogerson, 2013a in 2013b). Pojav in rast različnih oblik hotelov so spodbudili gradbeni vlagatelji, ki so prepoznali priložnosti, ki jih nudi segmentacija turističnega trga (Rogerson in Kotze, 2011, in Rogerson, 2012b).

V hitro spreminjajoči se hotelski dejavnosti je vloga nizkocenovnih hotelov še posebej zanimiva, saj so med hoteli v Južnoafriški republiki v preteklosti prevladovale nizkocenovne oblike nastanitve nizke kakovosti (Rogerson, 2011). Avtorica preučuje spremembe pomena, oblike in lokacije nizkocenovnih hotelov $\mathrm{v}$ državi ter $s$ tem prispeva nove izsledke $\mathrm{k}$ redkim raziskavam segmentacije trga in nizkocenovnih hotelov v gospodarstvih v vzponu, hotelske dejavnosti v podsaharski Afriki (Rogerson in Rogerson, 2011, ter Rogerson in Visser, 2011b) in nizkocenovnih hotelov v okviru mestnega turizma v Južnoafriški republiki (Rogerson in Visser, 2007 in 2011a). $Z$ vidika izzivov, s katerimi se srečujejo sodobna južnoafriška mesta, se večina raziskav urbane geografije osredotoča na vprašanja, ki so povezana z revnim mestnim prebivalstvom (glej na primer Moolla idr., 2011). Članek je odgovor na poziv Gustava Visserja (2013), ki je opozoril na potrebo po tem, da se morajo raziskovalci prenehati osredotočati samo na revno prebivalstvo $\mathrm{v}$ južnoafriških mestih v razvoju.

Članek metodološko temelji na analizi dveh obsežnih podatkovnih zbirk o vseh hotelih v Južnoafriški republiki leta 1990 in 2010 ter na pogovorih $\mathrm{z}$ glavnimi ponudniki nizkocenovnih hotelskih storitev v državi. Intervjuji so bili opravljeni z direktorji posameznih nizkocenovnih hotelov in z izvršnima direktorjema dveh največjih južnoafriških hotelskih verig. Obravnavana so bila različna vprašanja, povezana $\mathrm{z}$ nizkocenovnimi hoteli: zgodovina nizkocenovnih hotelov v Južnoafriški republiki, izboljšana kakovost sodobnih nizkocenovnih hotelov, spreminjajoča se umeščenost tovrstnih hotelov v državi in vrsta turistov, ki jih nizkocenovni hoteli pritegnejo. Članek je sestavljen iz treh delov. V prvem avtorica preučuje pojem segmentacije trga in mednarodne razprave o nizkocenovnih hotelih. V drugem delu obravnava razvoj in širjenje nizkocenovnih hotelov v Južnoafrǐ̌ki republiki, v zadnjem pa preučuje spreminjajočo se naravo in lokacijo nizkocenovnih hotelov od leta 1990 do danes.

\section{Segmentacija trga in nizkocenovni hoteli}

Segmentacija trga je razdelitev ali razcepitev trga na različne skupine ali segmente potrošnikov z izrazito podobnimi potrebami ter zahtevami po proizvodih in storitvah (Frank idr., 1972; Kotler, 1997, in Lattin, 2005). Bila naj bi temelj uspešnega trženjskega in poslovnega razvoja (McDonald in 
Dunbar, 2010). Na splošno velja, da je izredno pomembna za turistično dejavnost in upravljanje turističnih podjetij. $\mathrm{V}$ znanstvenih delih $s$ področja turizma se pojem uporablja $\mathrm{v}$ različnih raziskavah. Trenutno se raziskave segmentacije turistične dejavnosti osredotočajo predvsem na izdelavo profilov posameznih segmentov turistov in ugotavljanje, kateri osnovni dejavniki segmentacije lahko najnatančneje napovedo vedênje turistov (Tkaczynski idr., 2007).

Segmentacija trga je bila obsežno obravnavana v raziskavah nastanitvenega sektorja. Dallen Timothy in Victor Teye (2009) sta opravila mednarodno raziskavo nastanitvenega sektorja $\mathrm{v}$ razvitih državah in tistih v razvoju, ki je segmentiranost potrdila. Berger in Chiofaro Jr. (2007: 16) navajata, da so pred »dobo segmentacije trga mnoge velike hotelske verige le težko širile svojo znamko in povečevale dobiček, če niso ponovno vstopile na trge, na katerih so že imele dobro uveljavljen položaj«. V zadnjih nekaj desetletjih se je segmentacija trga v nastanitvenem sektorju pospešeno pojavljala po vsem svetu (Albrecht in Johnson, 2002, Graf, 2011). Ponudba različnih turističnih nastanitev je odziv na spremenjene trge, spremembe v gradnji in zlasti na nove potrošniške trende, ki zavračajo enovitost velikega dela komercialnega nastanitvenega sektorja (Freund de Klumbis in Musters, 2005; Aggett, 2007, ter Timothy in Teye, 2009). V zadnjih treh desetletjih je bil namen segmentacije trga oblikovanje nujno potrebne konkurenčne strategije rasti in širjenja velikih hotelskih verig (Cunill, 2006). V hotelskem sektorju Severne Amerike in Evrope naj bi bil proces segmentacije trga posledica dejstva, da potrošniki »iščejo vedno več nišnih proizvodov in storitev, ki bi zadovoljili njihove (nastanitvene) potrebe (Horner in Swarbrooke, 2005: 369).

Poleg zahtev potrošnikov po večji izbiri je bila tudi segmentacija trga sredstvo, $s$ katerim se velike mednarodne hotelske verige širijo, razvijajo svoje blagovne znamke in povečujejo dobičke (Berger in Chiofaro Jr., 2007). Onofre Martorell Cunill (2006) poudarja, da je bila segmentacija trga od 70. let 20. stoletja glavno gibalo in najpomembnejša konkurenčna strategija rasti in širjenja velikih hotelskih verig. Identične hotelske sobe posamezne hotelske verige so veljale za »morebitno konkurenčno slabost « (Lee, 2011: 708). Razdeljenost hotelskih storitev na prepoznavne skupine je zdaj že nekaj običajnega. Razvoj v smeri diferenciacije in segmentacije proizvodov v hotelski dejavnosti je odziv na širjenje standardnih škatlastih hotelov po svetu. Vpliv segmentacije je vse vidnejši tudi $v$ hotelski gradnji $\mathrm{v}$ gospodarstvih $\mathrm{v}$ vzponu. $\mathrm{V}$ primerjavi $\mathrm{z}$ drugimi območji svetovnega gospodarstva zelo malo znanstvenih del obravnava organizacijo hotelskega sektorja v državah v razvoju, zlasti z vidika nizkocenovnih hotelov.

Od 70. let in zlasti od začetka 80 . let 20. stoletja je bil za mednarodno hotelsko dejavnost značilen množičen pojav pojma nizkocenovnih hotelov, ki naj bi izviral iz Severne Amerike in Zahodne Evrope (Gilbert in Arnold, 1989, in Fiorentino, 1995). Pri analizi znanstvenih del o nizkocenovnih hotelih opazimo dve pomembni značilnosti. Prvič, kot rastoč segment svetovne hotelske dejavnosti nizkocenovni hoteli niso pritegnili pozornosti raziskovalcev; večina raziskav s tega področja se osredotoča na razvoj in izzive sektorja nizkocenovnih hotelov v Evropi in Severni Ameriki (Gilbert in Arnold, 1989; Gilbert in Lockwood, 1990; Fiorentino, 1995; Smith in Jenner, 1995; Brotherton, 2004; Teng, 2010; Blanco idr., 2011, ter Ruetz in Marvel, 2011). Drugič, novejše raziskave kažejo, da se je pojem nizkocenovnih hotelov geografsko razširil na gospodarstva $\mathrm{v}$ vzponu. Med redkimi raziskavami, ki preučujejo vidike rasti in poslovanja nizkocenovnih hotelov $\mathrm{v}$ gospodarstvih $\mathrm{v}$ vzponu, moramo omeniti raziskave Kitajske, ki so jih opravili Wen Hua idr.(2009), Wilco Chan in Shanshan Ni (2011), Rolly Huang in Mastura Chathoth (2011),Yu Qin idr. (2012) in Li Pan (2013), ter Malezije, ki so jih naredili Mastura Jaafar idr. (2011), Jaafar idr. (2012) ter Uma Munikrishnan in Bhuvanes Veerakumaran (2012).

Jasno je, da od konca 80. let vedno več raziskovalcev priznava, da so nizkocenovni hoteli poseben koncept gostinstva in turizma. V 90. letih je bilo takih hotelov že veliko in postali so več kot samo postranski turistični proizvod (Fiorentino, 1995: 455). Veljajo za uspešen primer segmentacije in znamčenja $\mathrm{v}$ širšem okviru upravljanja portfelja proizvodov (tehnike, ki so jo pred kratkim uvedle gostinske in turistične organizacije). Izraz »nizkocenovni hotel « pa se razlaga različno. $V$ eni od prvih raziskav se nanaša na ponudbo hrane, pijače in nastanitve in ne na izboljšanje kakovosti ali storitvenih vidikov hotelov (Gilbert in Arnold, 1989). David Gilbert in Andrew Lockwood (1990) menita, da so to hoteli, ki nudijo stalno zalogo varnih nastanitev na obrobnih območjih, na katerih običajno ni veliko restavracij, kakovost nastanitve pa je dokaj dobra. V drugih raziskavah so taki hoteli obravnavani kot majhni nizkocenovni hoteli z omejeno ponudbo, ki se pogosto enačijo s hoteli z omejenimi storitvami (Fiorentino, 1995, in TRI Hospitality Consulting, 2007). V evropskem okviru Ana Campos Blanco idr. (2011: 373) ugotavljajo, da so nizkocenovni hoteli »navadno postavljeni na najnižje mesto enačbe stroškovne učinkovitosti in nudijo najosnovnejšo nastanitev za krajše obdobje po ugodnih cenah «. V analizi cenovno ugodnih blagovnih znamk (2001) poudarjajo vedno večjo segmentacijo nizkocenovnih hotelov, pri čemer razlikujejo med štirimi kategorijami. Mnogi avtorji ugotavljajo, da ne moremo razlikovati med posameznimi vrstami nizkocenovnih hotelov, ampak da lahko tovrstne oblike nastanitve razvrstimo na nizkocenovne in supernizkocenovne oziroma $\mathrm{v}$ nizkocenovne, srednjecenovne in visokocenovne.

V skladu z ugotovitvami Alessandra Fiorentina (1995), svetovalnega podjetja TRI Hospitality Consulting (2007) in Ane 
Campos Blanco idr. (2011) so za pojem nizkocenovnih hotelov značilne določene strateške prvine. Taki hoteli izražajo kulturo in vrednote podjetja, ki mu pripadajo. Taki turistični proizvodi se razlikujejo od klasične nizkocenovne nastanitve, za katero je značilna nediferencirana tržna strategija, ki ni usmerjena v izbrane segmente potrošnikov. Nizkocenovni hoteli so namreč namenjeni poslovnim strankam, ljudem, ki veliko potujejo, družinam, počitnikarjem in turistom, ki obiskujejo svoje prijatelje in sorodnike. Čiste in udobne sobe z ustrezno opremo in ugodno ceno so najosnovnejši del ponudbe nizkocenovnih hotelov, ki so umeščeni na natančno določeni lokaciji. Ponudniki nastanitev poskušajo zagotoviti čim bolj edinstvene nizkocenovne storitve, in sicer tako, da spremenijo in prenovijo svoj način dela. Nizkocenovni hoteli temeljijo na prepoznavni podobi, ki jim omogoča, da si jih stranke zapomnijo kot zanesljive proizvode $s$ kakovostnimi storitvami po primerni ceni. Tovrstni hoteli so običajno na območjih z visokim pretokom ljudi, na primer ob glavnih cestah, na letališčih in v živahnih mestnih središčih. Stranke prihajajo iz najrazličnejših tržnih in družbenogospodarskih skupin (Fiorentino, 1995). Med njimi so tudi podjetja oziroma poslovneži, ki so prej hodili v dražje hotele $s$ celovito ponudbo storitev (Fiorentino, 1995, ter Blanco idr., 2011).

Nekateri raziskovalci se strinjajo, da »še vedno ni uveljavljene opredelitve nizkocenovnih hotelov, zaradi česar jih je težko uvrstiti v obstoječe kategorije « (Fiorentino 1995: 455). Izraz »nizkocenovni hotel « je moden, vendar gre za napačno poimenovanje, saj namiguje na enovit proizvod. V resnici gre za izredno segmentiran pojav (Roper in Carmouche, 1989), ki pa ima skupno značilnost - nizkocenovni hoteli se na lestvici kakovosti hotelske ponudbe navadno enačijo s hoteli z eno zvezdico ali dvema. To opredelitev so povzeli številni raziskovalci (Gilbert in Lockwood, 1990; TRI Hospitality Consulting, 2007, ter Blanco idr., 2011), uporabili pa smo jo tudi v južnoafriški analizi, predstavljeni v nadaljevanju.

\section{Nizkocenovni hoteli in zgodovinski razvoj južnoafriške hotelske dejavnosti}

Večino hotelov v Južnoafriški republiki, ki so bili zgrajeni do konca 80. let 20. stoletja, lahko uvrstimo v kategorijo nizkocenovnih oblik nastanitve. $\mathrm{V}$ obdobju apartheida in zlasti po uporu v Sowetu leta 1976 je bil državni turizem podvržen bojkotom in mednarodnim sankcijam (Rogerson in Visser, 2004). Zaradi tega je bil večji del hotelske dejavnosti izključen iz mednarodnih turističnih trgov in se je osredotočal na zadovoljevanje potreb domačega trga, ki so ga skoraj v celoti sestavljali belci. Pomembna značilnost zgodovinskega razvoja hotelske dejavnosti je bila povezava s prodajo alkoholnih pijač. Ta je določala južnoafriško hotelsko dejavnost med letoma 1920 in 1970 in šele po tem obdobju je del dejavnosti svojo glavno storitev preusmeril na zagotavljanje prenočǐšč (Rogerson, 2011).

Glavna značilnost zgodnje hotelske dejavnosti v Južnoafriški republiki je bila torej prodaja alkoholnih pijač, kar je bila »posledica vladne politike, ki je do 60. let 20. stoletja načelno podpirala gospodarski razvoj prek rasti turizma, $\mathrm{v}$ praksi pa je želela obvladovati lokale, v katerih se je točil alkohol « (Caras, 2007: 106). V skladu z zakonskimi določbami je »dovoljenje za točenje alkohola lahko prejel vsak lokal z desetimi sobami, ki je stregel tople obroke, zato so mnoge pivnice svoji ponudbi preprosto dodale deset sob z najosnovnejšo opremo, da so dobile dovoljenje « (Caras, 2007: 106). Arthur Norval (1936) in Christian Rogerson (2011) v svojih delih natančno opisujeta zgodnje povezave med industrijo alkoholnih pijač in razvojem hotelov v Južnoafriški republiki. Za prodajo alkoholnih pijač je bil pomemben pojav sistema povezanih hiš (ang. tied house system). V tem sistemu je postala prodaja alkoholnih pijač »najpomembnejša funkcija povezanih ali nadzorovanih hotelov «, zaradi česar je nastanitvena funkcija postala drugotnega pomena (Norval, 1936; Caras, 2007, in Rogerson, 2011). Zakonodajni okvir razvoja južnoafriške hotelske dejavnosti v 20. stoletju je torej temeljil na zakonodaji o prodaji alkoholnih pijač, zaradi česar je večina hotelov $\mathrm{v}$ državi obratovala predvsem kot prodajalna alkoholnih pijač in ne kot ponudnik prenočiščc.

Šele z zakonodajnimi spremembami konec 60. let 20. stoletja je prodaja alkoholnih pijač postopoma oslabela in začel se je oblikovati hotelski sektor, ki je temeljil na dobičkonosnosti nastanitvenih storitev. Spremembe v zakonodaji hotelske dejavnosti, ki jih je sprejela vlada, so po letu 1965 spodbudile proces prestrukturiranja, pospešile pa so ga predvsem $\mathrm{v} 70$. letih, kar je bila »deloma zasluga ukrepov hotelske verige Southern Sun Hotels « (Saunders in Barben, 2007: 27). Razvoj sodobne hotelske dejavnosti v Južnoafriški republiki je bil močno povezan $s$ pojavom in krepitvijo velikih hotelskih verig, med katerimi je bila najpomembnejša prav omenjena hotelska veriga. Po 70. in 80. letih se je začela hotelska dejavnost bolj diferencirati, saj je bilo v večjih mestih (Johannesburg, Durban in Cape Town) ustanovljeno veliko visokokakovostnih hotelov. Novogradnje so financirale nastajajoče hotelske verige in v 70. letih je južnoafriški hotelski sektor cvetel. Konec desetletja se je lahko »država ponašala s hoteli mednarodno primerljive kakovosti v vseh največjih mestih « (Caras, 2007: 107). Dodaten val hotelskih gradenj je konec 70 . in začetek 80. let spodbudila gradnja velikih kompleksov, povezana z igralništvom in ustanavljanjem velikih igralnic v domnevno neodvisnih bantustanih, ki so bili plod načrtovalske prakse v obdobju apartheida (Rogerson, 1990). 
Preglednica 1: Skupno število hotelov in hotelskih sob v Južnoafriški republiki leta 1990

\begin{tabular}{lllll}
\hline število zvezdic & število hotelov & odstotek & število sob & odstotek \\
\hline nerazvrščeni & 13 & 1,3 & 414 & 1,0 \\
\hline ena & 598 & 59,6 & 13.456 & 32,2 \\
\hline dve & 223 & 22,2 & 10.678 & 25,6 \\
\hline tri & 107 & 10,7 & 10.008 & 24,0 \\
\hline štiri & 42 & 4,2 & 3.799 & 9,1 \\
\hline pet & 20 & 2,0 & 3.395 & 8,1 \\
\hline skupaj & 1.003 & 100 & 41.750 & 100 \\
\hline
\end{tabular}

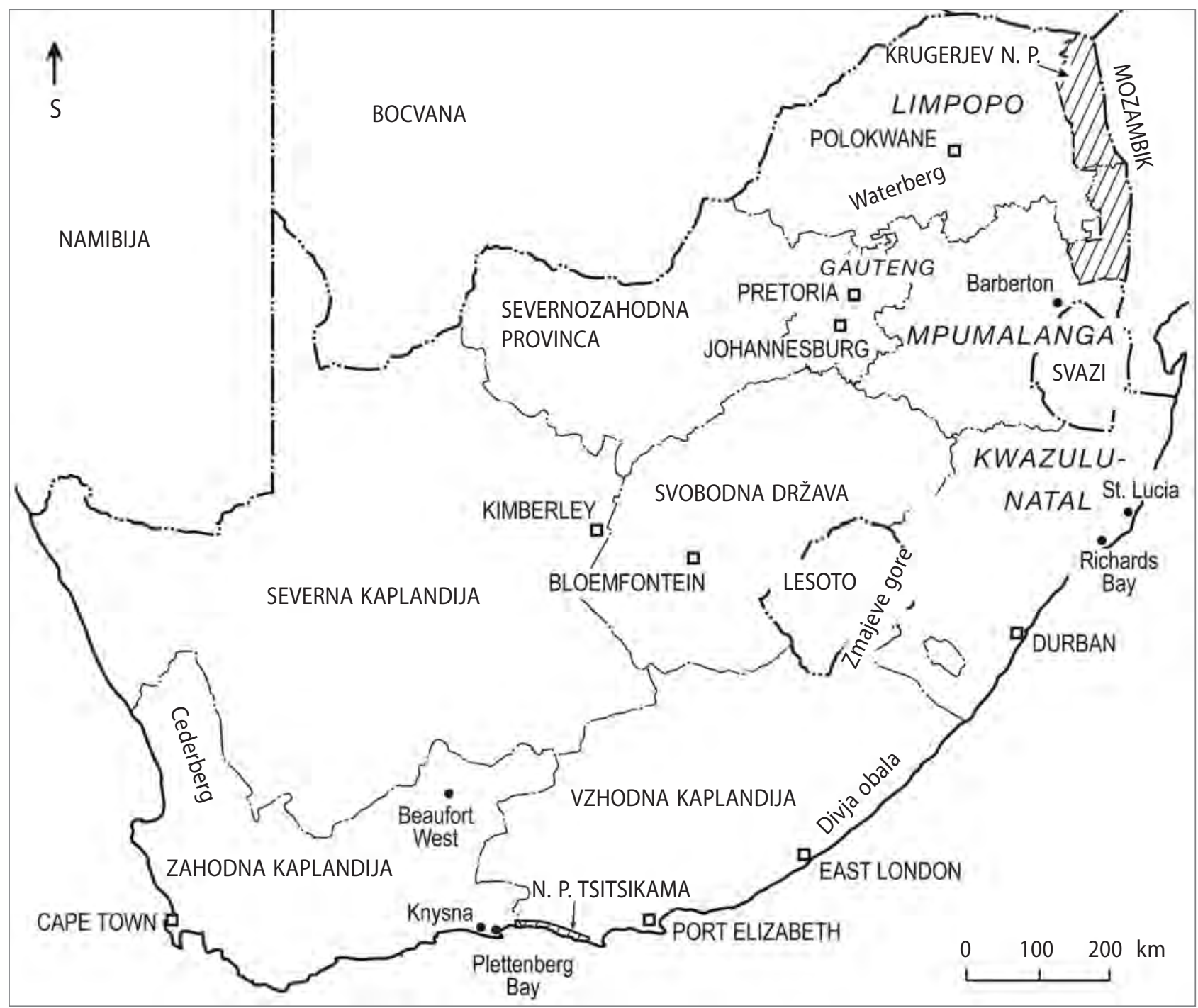

Slika 1: Največja mesta in turistične znamenitosti v Južnoafriški republiki

$\mathrm{Za} 70$. in 80. leta je bil značilen pojav nove hotelske ponudbe, ki se je osredotočala na prostočasne dejavnosti in je postavila temelje hotelskemu sektorju, ki je ponujal veliko več kot poceni prenočišča, povezana s prodajo alkoholnih pijač. Veriga Southern Sun Group je v teh dveh desetletjih še naprej krepila dejavnost srednjecenovnih in višjecenovnih hotelov s celovito ponudbo storitev, v začetku 80. let pa so v Južnoafriški republiki začele delovati tudi druge hotelske verige. Med najpomembnejšimi sta bili skupina Protea, ki je začela obratovati leta 1984 ter je ustvarila verigo srednjecenovnih in višjecenovnih hotelov s celovito ponudbo storitev po vsej državi, in hotelska veriga City Lodge, ki je v Južnoafriški republiki uvedla prenovljen koncept hotelov z omejeno ponudbo (Rogerson, 2011b).

\section{Spremembe segmenta nizkocenovnih hotelov v Južnoafriški republiki}

Po letu 1990 se je južnoafriška hotelska dejavnost začela preoblikovati in se prilagajati rastočemu mednarodnemu turistične- 
Preglednica 2: Število hotelov in hotelskih sob v Južnoafriški republiki leta 2010

\begin{tabular}{lllll}
\hline število zvezdic & število hotelov & odstotek & število sob & odstotek \\
\hline nerazvrščeni & 19 & 1,7 & 532 & 0,7 \\
\hline ena & 199 & 17,4 & 6.692 & 9,1 \\
\hline dve & 73 & 6,4 & 3.258 & 4,4 \\
\hline tri & 377 & 32,9 & 29.439 & 40,2 \\
\hline štiri & 335 & 29,2 & 23.151 & 31,6 \\
\hline pet & 162 & 14,1 & 10.180 & 13,9 \\
\hline skupaj & 1.165 & 100 & 73.252 & 100 \\
\hline
\end{tabular}

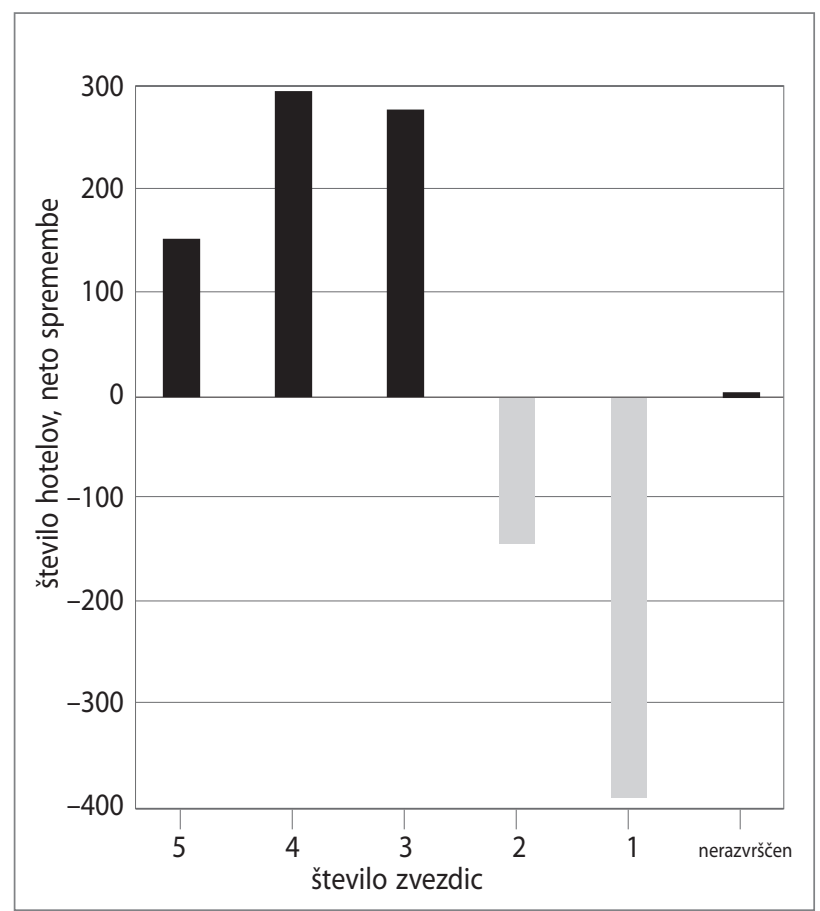

Slika 2: Neto spremembe števila hotelov v Južnoafriški republiki med letoma 1990 in 2010

mu trgu, saj so bile mednarodne sankcije odpravljene, število mednarodnih turistov v državi pa se je močno povečalo (Rogerson, 2013a, 2013b). Ob tem se je opazno spremenila tudi vloga nizkocenovnih hotelov. $\mathrm{V}$ tem poglavju obravnavamo vpliv teh sprememb na položaj nizkocenovnih hotelov v južnoafriški hotelski industriji ter njihovo spreminjajočo se naravo in lokacijske vzorce od leta 1990 do danes.

Zaradi zakonodaje o prodaji alkoholnih pijač in nerazvitega mednarodnega turizma so leta 1990 največji delež hotelov v državi predstavljali hoteli z eno zvezdico ali dvema (preglednica 1). Leta 1990 je bilo v državi 821 nizkocenovnih hotelov, torej hotelov z eno zvezdico ali dvema. Razpršeni so bili po vsej državi, od velikih mestnih središč do majhnih mest. Kot je razvidno iz preglednice 1 , so več kot 80 \% južnoafriške hotelske dejavnosti sestavljali poceni hoteli nizke kakovosti, velik del teh pa so bile prodajalne alkoholnih pijač z nekaj sobami. $57,8 \%$ vseh hotelskih sob v državi je bilo v nizkocenovnih hotelih. Manjši delež je posledica majhne velikosti hotelov, katerih dejavnost temelji na prodaji alkoholnih pijač. Prav ta prevlada nizkocenovnih hotelov $\mathrm{v}$ celotnem fondu hotelov je omejevala konkurenčnost turizma $\mathrm{v}$ Južnoafriški republiki (Rogerson, 2013a).

Po letu 1990 (in zlasti po letu 1994) je dobro vidna rast števila mednarodnih turistov, ki so $\mathrm{v}$ Južnoafriško republiko pripotovali z dolgimi poleti, da bi obiskali najpomembnejše turistične znamenitosti (slika 1). Sledil je val gradnje novih hotelov, ki naj bi nastanili premožnejše turiste, ki so zamenjali domače turiste in $s$ tem tudi glavni tržni segment južnoafriške turistične dejavnosti (Rogerson, 2012b in 2013a). Razcvet gradnje višjecenovnih hotelov je med letoma 2005 in 2010 spodbudila organizacija Fifinega svetovnega nogometnega prvenstva leta 2010. Južnoafriška republika je namreč zmagala na natečaju za organizacijo tega prvenstva, kar je spodbudilo neutemeljena pričakovanja, da bodo ta megalomanski dogodek obiskale trume turistov. Zlasti v Cape Townu je bilo zato zgrajeno preveč razkošnih hotelov (Ferreira, 2011, ter Ferreira in Boshoff, v tisku).

Temeljno prestrukturiranje, do katerega je v južnoafriški hotelski industriji prišlo po spremembi politične ureditve, je jasno razvidno iz preglednice 2, v kateri je navedeno število hotelov in hotelskih sob leta 2010. Zaradi novih priložnosti mednarodnega turizma od začetka 90. let so hoteli v Južnoafriški republiki glavno dejavnost preusmerili od prodaje alkoholnih pijač k prenočiščcem. Po spremembi politične ureditve južnoafriško hotelsko dejavnost obvladujejo predvsem tri vodilne hotelske verige: Protea, Tsogo Sun (Southern Sun) in City Lodge. Vse tri imajo lokalne lastnike in upravnike. Vsaka je svojo ponudbo poskušala čim bolj razvejiti, da bi pritegnila čim različnejše skupine turistov. Hotelska veriga Protea ima v lasti 84 hotelov in je tako največje afriško hotelsko podjetje. Svoje hotele s tremi, štirimi in petimi zvezdicami je razširila z neposrednim lastništvom, upravljavskimi pogodbami in $s$ franšiznimi sporazumi. Do leta 2012 se je veriga Tsogo Sun (prej znana pod imenom Southern Sun) razvila v krovno blagovno znamko, $v$ katero so spadale različne znamke hotelov $s$ tremi in štirimi zvezdicami s celovito ponudbo storitev. Veriga City 


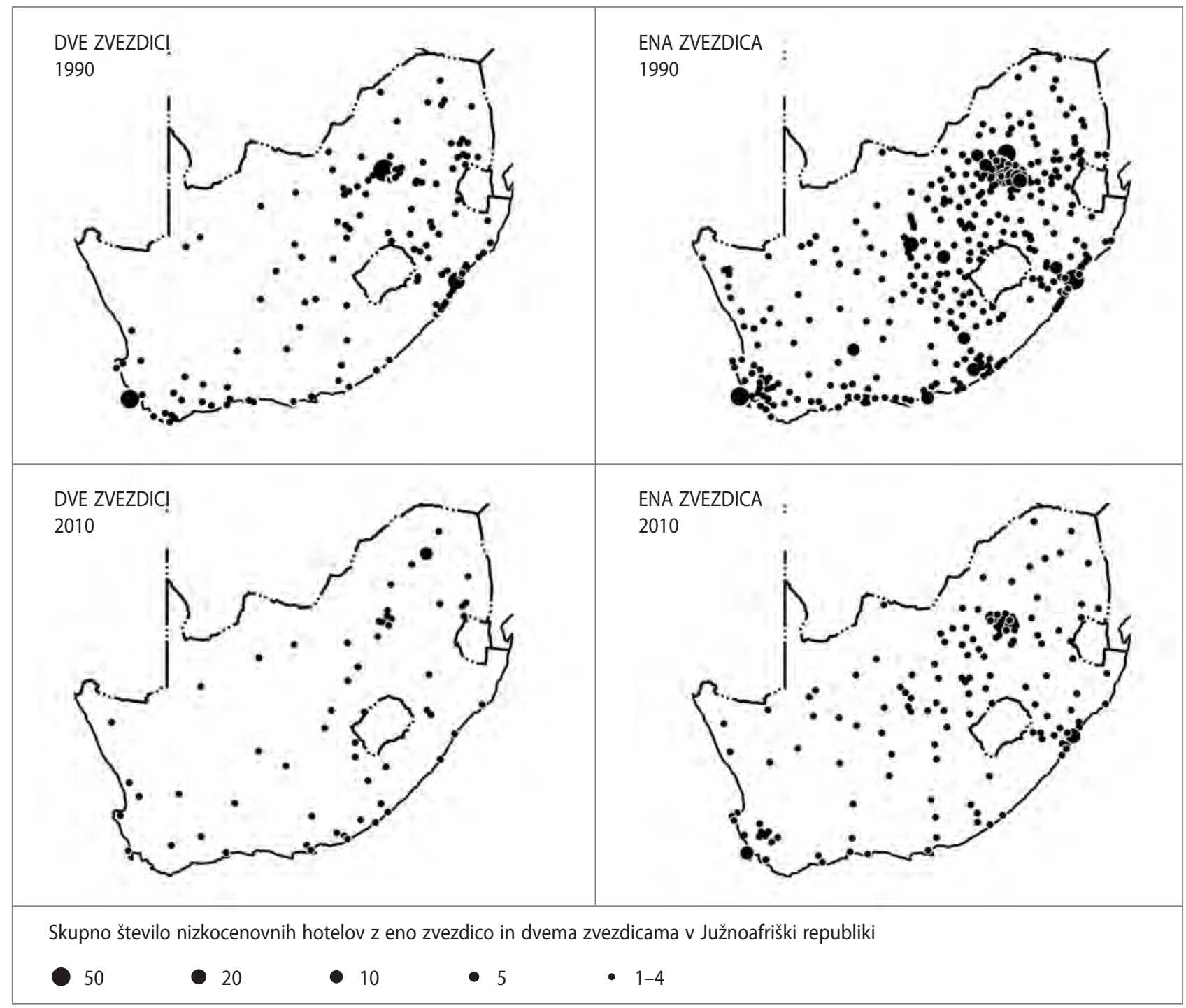

Slika 3: Južnoafriški nizkocenovni hoteli z eno zvezdico ali dvema leta 1990 in 2010

Lodge ima v lasti hotele $z$ eno zvezdico, dvema zvezdicama, $s$ tremi in štirimi zvezdicami, večinoma pa gre za hotele z omejenimi storitvami (Rogerson, 2012b).

Do izboljšanja kakovosti hotelske dejavnosti v državi je prišlo po izgradnji več kakovostnih hotelov in prenovi nekaterih hotelov. Leta 1990 so hoteli z eno zvezdico ali dvema predstavljali več kot $80 \%$ skupnega hotelskega fonda, leta 2010 pa je njihov delež padel pod četrtino. Število višjecenovnih razkošnih hotelov s štirimi ali petimi zvezdicami pa se je močno povečalo. Leta 1990 sta ti kategoriji hotelov predstavljali 6,2 \% vseh hotelov, leta 2010 pa že $43,3 \%$. Skladno s tem se je delež nizkocenovnih hotelov z eno zvezdico ali dvema v celotnem hotelskem fondu z 81,8 \% leta 1990 zmanjšal na 23,5 \% leta 2010. Če pogledamo skupno število hotelskih sob, se je delež nizkocenovnih hotelov še bolj znižal. Leta 1990 je bilo v nizkocenovnih hotelih $23 \%$ vseh hotelskih sob v državi, leta 2010 pa je njihov delež padel pod $14 \%$ (preglednica 2).
Neto spremembe števila hotelov med letoma 1990 in 2010 so prikazane na sliki 2. Vidna je hitra rast deleža hotelov $s$ tremi, štirimi in petimi zvezdicami ter popoln upad števila hotelov z eno zvezdico in dvema zvezdicama. Da se je splošna kakovost hotelov $\mathrm{v}$ državi izboljšala, potrjuje tudi podatek, da je bilo leta $1990 \mathrm{v}$ državi samo 20 hotelov s petimi zvezdicami, leta 2010 pa se je njihovo število povečalo na 162. Po drugi strani je bilo leta $1990 \mathrm{v}$ državi 598 hotelov z eno zvezdico, leta 2010 pa samo še 199. Spremembe v južnoafriški hotelski dejavnosti med letoma 1990 in 2010 lahko vidimo z analizo sprememb, s katero določimo vzorce pojavljanja novih in propadanja starih hotelov. Analiza je pokazala, da je bilo v preučevanem obdobju v državi zgrajeno samo 94 hotelov z eno zvezdico ali dvema, kar je samo 11,7 \% vseh novozgrajenih hotelov. Obenem je do leta 2010 prenehalo delovati 547 hotelov z eno zvezdico ali dvema, kar je bilo med letoma 1990 in 2010 85,5 \% vseh propadlih hotelov v Južnoafriški republiki. Analiza razkriva, da je bil glavni vzrok propada nizkocenov- 


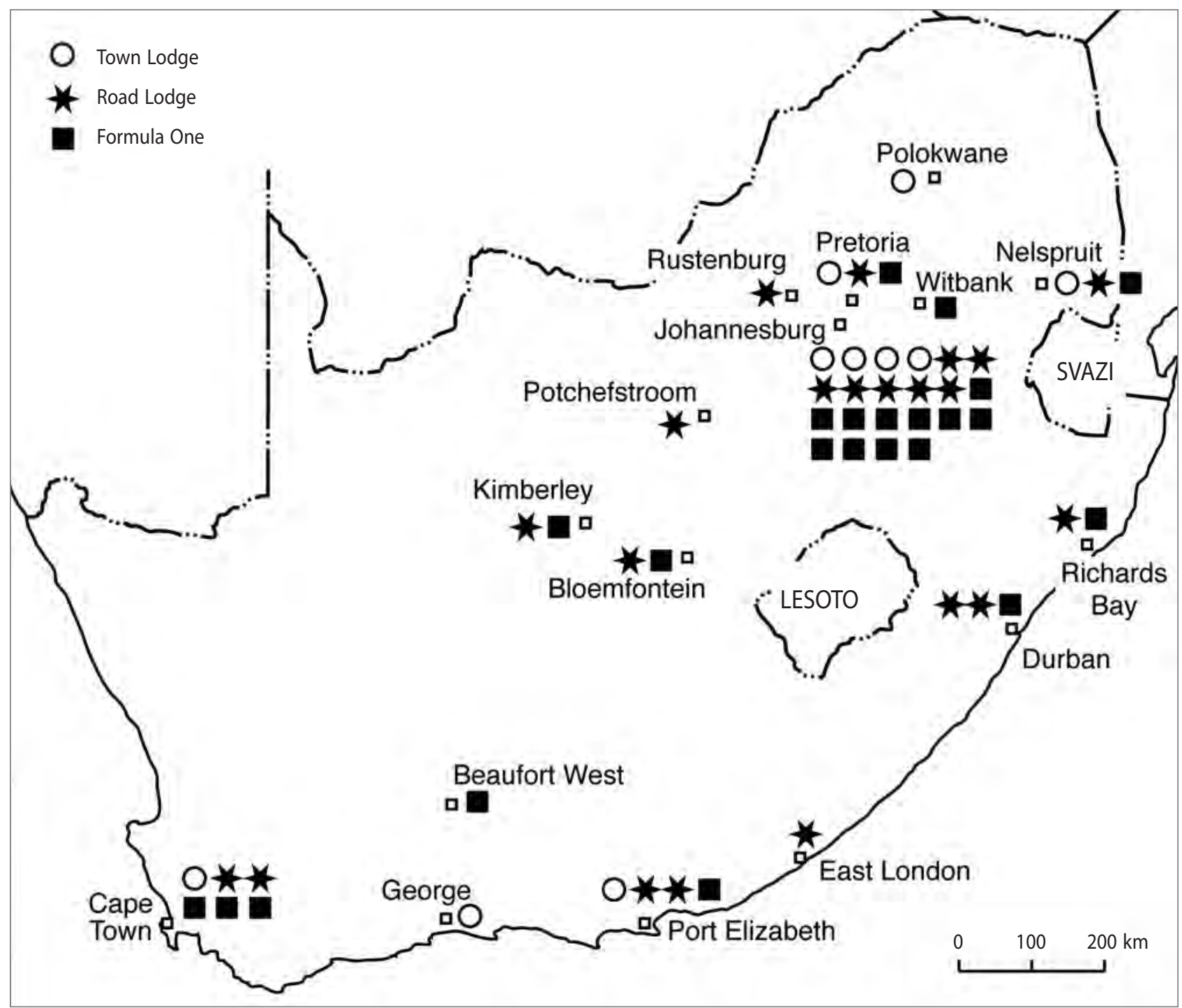

Slika 4: Verige nizkocenovnih hotelov leta 2010 (vir: City Lodge Hotels Limited, 1990 in 2010, in Tsogo Sun Hotels Limited, 2010)

nih hotelov zaprtje velikega števila hotelov, ki so prej služili s prodajo alkoholnih pijač.

Spremembe $\mathrm{v}$ južnoafriški nizkocenovni hotelski dejavnosti se kažejo tudi v vzorcih lokacije hotelov. Na sliki 3 je prikazana lokacija hotelov z eno zvezdico in dvema zvezdicama za leti 1990 in 2010. Leta 1990 so bili nizkocenovni hoteli razpršeni po mestih po vsej državi. Največ hotelov z eno zvezdico in dvema zvezdicama je bilo na glavnih metropolitanskih območjih, zlasti v Johannesburgu in okoliških občinah ter v Durbanu, Cape Townu in Pretorii. Leta 2010 se je močno zmanjšal geografski obseg tovrstnih hotelov zaradi zaprtja velikega števila samostojnih poceni hotelov zunaj glavnih metropolitanskih območij. Ti hoteli so na veliko območjih preprosto izginili, običajno pa so jih zamenjale druge oblike nastanitev, kot so manjši polpenzioni, apartmaji in turistične kmetije. Čeprav je bilo klasičnih nizkocenovnih hotelov vse manj tudi v manjših mestih, jih je največ vendarle izginilo v največjih mestih. $\mathrm{Na}$ primer, med letoma 1990 in 2010 se je v Johannesburgu število hotelov z eno zvezdico zmanjšalo s 56 na 20, število hotelov z dvema zvezdicama pa s 25 na 6. Drugi največji upad tovrstnih hotelov je viden v občini Ekurhuleni blizu Johannesburga, v kateri se je število hotelov z eno zvezdico zmanjšalo z 38 na 15, število hotelov z dvema zvezdicama pa s 6 na 2.

S preoblikovanjem južnoafriške hotelske dejavnosti se je po letu 1990 spremenila tudi podoba prej prevladujočih nizkocenovnih hotelov slabe kakovosti, ki so služili predvsem s prodajo alkoholnih pijač. Eden od vidikov prestrukturiranja južnoafriške hotelske dejavnosti je tudi pojav novih inovativnih oblik nizkocenovnih hotelov. Skoraj vseh 94 novih hotelov z eno zvezdico ali dvema, zgrajenih med letoma 1990 in 2010, je nove oblike, ki posnemajo slog nizkocenovnih hotelov v Severni Ameriki in Evropi. Val novih hotelov z eno zvezdico ali dvema so ustanavljale različne lokalne južnoafriške hotelske verige, zlasti Tsogo Sun in City Lodge. Te nove oblike so bile 
namenjene nastajajočemu trgu poslovnih turistov in počitnikarjev, ki so iskali kakovostno nastanitev po ugodni ceni. $\mathrm{Na}$ sliki 4 je prikazana lokacija novih hotelov v Južnoafriški republiki. Večina hotelov, ki sta jih ustanovili verigi City Lodge in Tsogo Sun, je bila zgoščena v večjih mestih in sekundarnih središčih, namenjena pa je bila predvsem domačim poslovnim turistom in počitnikarjem. Town Lodge je znamka hotelov z dvema zvezdicama z omejenimi storitvami v lasti verige City Lodge, Road Lodge pa je znamka hotelov z eno zvezdico z omejenimi storitvami, prav tako v lasti verige City Lodge, ki se nahajajo na petih glavnih letališčih $\mathrm{v}$ državi ter na glavnih metropolitanskih območjih in v sekundarnih središčih. Hoteli Formula One so del znamke Accor, ki je v lasti verige Tsogo Sun. Gre za hotele z eno zvezdico, ki ponujajo »sodobno in praktično nastanitev brez odvečnega dekorja in sitnosti « (Tsogo Sun Hotels Limited, 2010). Vsi ti hoteli se nahajajo na metropolitanskih območjih ali sekundarnih središčih na ugodnih lokacijah blizu glavnih prometnih povezav in letališč. Skladno s tem lahko po letu 1990 opazimo dva procesa sprememb v nizkocenovnem hotelskem sektorju. Po eni strani so se zaprli mnogi nekdanji nizkocenovni hoteli slabe kakovosti, ki so bili neločljivo povezani s prodajo alkoholnih pijač, po drugi strani pa so bili ustanovljeni novi nizkocenovni hoteli, ki so namenjeni novemu segmentu poslovnih turistov in počitnikarjev $\mathrm{v}$ postapartheidski Južnoafriški republiki.

\section{Sklep}

Od 80. let 20. stoletja je bila za hotelski sektor v Južnoafriški republiki značilna močna segmentacija trga. Iskanje novih tržnih segmentov je za velika hotelska podjetja » postalo prava znanost « (Berger in Chiofaro Jr., 2007: 16). Jasno je, da sta rast in geografska širitev pojava nizkocenovnih hotelov del širše segmentacije svetovne hotelske dejavnosti. Čeprav se turistični in gostinski strokovnjaki strinjajo, da nizkocenovni hoteli po svetu rastejo in se širijo, doslej ni bilo opravljenih veliko raziskav na tem področju (Gilbert in Arnold, 1989; Fiorentino, 1995, ter Blanco idr., 2011). V večini razpoložljivih raziskav se je preučeval sektor cenovno ugodnih hotelov v Severni Ameriki in Evropi. Pojav cenovno ugodnih hotelov se je razširil v hotelsko industrijo več držav v razvoju, zaradi česar bi morale biti v raziskave tovrstnih hotelov vključene tudi države podsaharske Afrike, v katerih se hoteli le redko preučujejo (Rogerson in Rogerson, 2011, ter Rogerson in Visser, 2011b).

V članku opisana raziskava kaže, da ima sektor nizkocenovnih hotelov v Južnoafriški republiki pomembno vlogo pri razvoju hotelske dejavnosti. Vse do leta 1990 so tovrstni hoteli predstavljali največji delež hotelov v državi. Zaradi ponovne vključitve postapartheidske Južnoafriške republike v svetovni turizem je prišlo do preusmeritve turistične infrastrukture in hotelskih proizvodov, ki naj bi zadovoljili potrebe vse večjega števila mednarodnih turistov, ki prihajajo v državo. Zaradi tega se je zmanjšala vloga nizkocenovnih hotelov. Pri obravnavi cenovno ugodne hotelske dejavnosti je treba upoštevati različne plasti tovrstnih hotelov, ki so bile oblikovane v državi. Obravnavani sektor je razdeljen na vse manjšo skupino starejših hotelov slabe kakovosti, na katerih je v letih pred spremembo politične ureditve temeljila hotelska dejavnost v državi, in vedno številčnejše nizkocenovne hotele, ki posnemajo slog Severne Amerike in Evrope. Ti novejši hoteli so inovativen proizvod, $s$ katerim so se vodilne južnoafriške hotelske verige odzvale na novo tržno nišo.

Za spremembo lokacije nizkocenovnih hotelov v Južnoafriški republiki sta značilna dva vzporedna procesa. Poleg zmanjšane vloge in zapiranja večine prejšnjih poceni hotelov nizke kakovosti, ki so služili s prodajo alkoholnih pijač, je v mestih opazna rast nove oblike cenovno ugodnih hotelov, ki nudijo nastanitve novemu segmentu poslovnih turistov in počitnikarjev, ki se je izoblikoval po spremembi politične ureditve. $V$ manjših mestih sta prav tako opazni spremembi v povezavi s starejšimi poceni hoteli, ki so se ukvarjali s prodajo alkoholnih pijač. $V$ večini manjših mest so se zaradi splošnega gospodarskega upada tega področja v zadnjih dveh desetletjih ti hoteli preprosto zaprli (Nel in Rogerson, 2007). V mestih, v katerih je gospodarstvo zaradi turističnega razvoja ponovno oživelo, pa se kakovost lokalnih nastanitvenih storitev izboljšuje. Stari nizkocenovni hoteli se zamenjujejo z novimi oblikami lokalnih turističnih nastanitev, kot so gostišča in polpenzioni.

\section{Jayne M. Rogerson}

University of Johannesburg, Department of Geography, Enviro-

nmental Management and Energy Studies, Johannesburg, Južnoafriška republika

E-pošta: jayner@uj.ac.za

\section{Zahvala}

Rada bi se zahvalila Wendy Job za oblikovanje vseh slik in Skye Norfolk za uporabne nasvete pri prejšnjih različicah članka.

\section{Viri in literatura}

Aggett, M. (2007): What has influenced growth in the UK's boutique hotel sector? International Journal of Contemporary Hospitality Management, 19(2), str. 169-177. DOI: 10.1108/09596110710729274

Albrecht, D., in Johnson, E. (2002): New hotels for global nomads. London, Merrill.

Azmy, N. H., in Atef, T. M. (2011): The Egyptian government's role in re-establishing the hotel industry in Cairo (1953-1957). International Journal of Hospitality and Tourism Administration, 12(3), str. 225-251. DOI: 10.1080/15256480.2011.590741

Bégin, S. (2000): The geography of a tourist business: Hotel distribution and urban development in Xiamen, China. Tourism Geographies, 2(4), str. 448-471. DOI: 10.1080/146166800750035530

Berger, B. B., in Chiofaro Jr., D. J. (2007): Select-service hotels: A guide 
to understanding the lodging industry and one of its most attractive segments. Magistrska naloga. Boston, Massachusetts Institute of Technology.

Blanco, A. C., Oehmichen, A., in Frood, S. (2011): European hotel development: Focus on budget hotels. Journal of Retail \& Leisure Property, 9(2), str. 373-379. DOI: 10.1057/rlp.2011.1

Brotherton, B. (2004): Critical success factors in UK budget hotel operations. International Journal of Operations and Production Management, 24(9), str. 944-969.

Caras, D. (2007): Managing accommodation for tourists. V: George, R. (ed.): Managing tourism in South Africa, str. 103-120. Cape Town, Oxford University Press.

Chan, W. W., in Ni, S. (2011): Growth of budget hotels in China: Antecedents and future. Asia Pacific Journal of Tourism Research, 16(3), str. 249-262. DOI: 10.1080/10941665.2011.572659

City Lodge Hotels Limited (1990): Annual report. Johannesburg.

City Lodge Hotels Limited (2010): Annual report. Johannesburg.

Cunill, O. M. (2006): The growth strategies of hotel chains: Best busines practices by leading companies. New York, Haworth Hospitality Press.

Ferreira, S. (2011): South African tourism road to recovery: 2010 FIFA Soccer World Cup as a vehicle. Tourism Review International, 15(1-2), str. 91-106. DOI: 10.3727/154427211X13139345020372

Ferreira, S. L., in Boshoff, A. (v tisku): Post-2010 FIFA Soccer World Cup: Oversupply and location of luxury hotel rooms in Cape Town. Current Issues in Tourism. DOI: 10.1080/13683500.2013.776524

Fiorentino, A. (1995): Budget hotels: Not just minor hospitality products. Tourism Management, 16(6), str. 455-462.

Frank, R. E., Massy, W. F., in Wind, Y. (1972): Market segmentation. Englewood Cliffs, NJ, Prentice Hall.

Freund de Klumbis, D. F., in Musters, W. (2005): Developments in the hotel industry: Design meets historic properties. V: Sigala, M., in Leslie, D. (ur.): International Cultural Tourism, str. 26-39. Oxford, Butterworth-Heinemann.

Gilbert D. C., in Arnold, L. (1989): Budget hotels. Leisure Management, 9(2), str. 61-63.

Gilbert, D. C., in Lockwood, A. (1990): Budget hotels - the USA, France and UK compared. Travel \& Tourism Analyst, 3(1), str. 19-35.

Graf, N. S. (2011): Market structure and demand-side substitutability of chained urban hotel segments. International Journal of Hospitality Management, 30(1), str. 82-90. DOI: 10.1016/j.ijhm.2010.03.011

Hall, C. M., in Page, S. J. (2006): The geography of tourism and recreation: Environment, place and space. London, Routledge.

Horner, S., in Swarbrooke, J. (2005): Leisure marketing: A global perspective. Oxford, Butterworth-Heinemann.

Hua, W., Chan, A., in Mao, Z. (2009): Critical success factors and customer expectation in budget hotel segment - A case study of China. Journal of Quality Assurance in Hospitality \& Tourism, 10(1), str. 59-74. DOI: 10.1080/15280080802713702

Huang, R. S., in Chathoth, P. K. (2011): Leasing as a modal choice in China's company-run budget hotels: An exploratory study. Tourism Planning \& Development, 8(1), str. 37-50. DOI: 10.1080/21568316.2011. 554045

Jaafar, M., Aziz, A. R. A., in Sukarno, S. Z. M. (2012) :Tourism marketing: An overview of small and medium budget hotels (SMBHs). Asia Pacific Journal of Tourism Research, 17(1), str. 1-13.

DOI: 10.1080/21568316.2011.554045
Jaafar, M., Ing, T. K., in Sukarno, S. Z. M. (2011): Problems of small and medium budget hotel operators. World Applied Sciences Journal, 12(10), str. 73-79.

Kotler, P. (1997): Marketing management: Analysis, planning, implementation and control. Englewood Cliffs, NJ, Prentice Hall.

Lattin, G. W. (2005): The lodging and food service industry. Lansing, Educational Institute American Hotel and Lodging Association.

Lee, C. G. (2011): The determinants of hotel room rates: Another visit with Singapore's data. International Journal of Hospitality Management, 30(3), str. 756-758. DOI: 10.1016/j.jijhm.2010.09.010

McDonald, M., in Dunbar, I. (2010): Market segmentation: How to do it, how to profit from it. Oxford, Goodfellow Publishers.

McNeill, D. (2008): The hotel and the city. Progress in Human Geography, 32(3), str. 383-398. DOI: 10.1177/0309132508089096

McNeill, D. (2009): The airport hotel as business space. Geografiska Annaler: Series B Human Geography, 91(3), str. 219-228. DOI: 10.1111/j.1468-0467.2009.00316.x

McNeill, D., in McNamara, K. (2009): Hotels as civic landmarks, hotels as assets: The case of Sydney's Hilton. Australian Geographer, 40(3), str. 369-386. DOI: 10.1080/00049180903127796

McNeill, D., in McNamara, K. (2012): The life and death of great hotels: A building biography of Sydney's "The Australia". Transactions of the Institute of British Geographers, 37(1), str. 149-163. DOI: 10.1111/j.1475-5661.2011.00445.x

Medlik, S., in Ingram, H. (2000): The business of hotels. Oxford, Butterworth-Heinemann.

Moolla, R., Kotze, N., in Block, L. (2011): Housing satisfaction and quality of life in RDP houses in Braamfischerville, Soweto: A South African case study. Urbani izziv, 22(1), str. 138-143.

DOI: 10.5379/urbani-izziv-en-2011-22-01-005

Munikrishnan, U. T., in Veerakumaran, B. (2012): A survey on business success factors influencing budget hotels in Klang Valley. Journal of Global Entrepreneurship, 2(1), str. 21-35.

Nel, E., in Rogerson, C. M. (2007): Evolving local economic development policy and practices in South Africa with special reference to smaller urban centres. Urban Forum, 18(2), str. 1-11.

DOI: $10.1007 / \mathrm{s} 12132-007-9003-8$

Niewiadomski, P. (2009): Different forms of expansion of international hotel groups and the processes of regional development in Central and Eastern Europe. Prispevek je bil predstavljen na konferenci z naslovom EGRG Postgraduate Symposium, ki je potekala 6. maja v Londonu v Veliki Britaniji. Tipkopis

Norval, A. J. (1936): The tourist industry: A national and international survey. London, Pitman.

Pan, L. (2013): Five-force analysis and market strategies of budget hotels in small and medium-sized cities. V: Du, W. (ed.): Informatics and management science $V 1$, str. 331-337. London, Springer. DOI: 10.1007/978-1-4471-4805-0_39

Qin, Y., Adler, H., in Cai, L. A. (2012): Successful growth strategies of three Chinese domestic hotel companies. Journal of Management and Strategy, 3(1), str. 40-54. DOI: 10.5430/jms.v3n1p40

Rogerson, C. M. (1990): Sun international: The making of a South African tourism multinational. GeoJournal, 22(3), str. 345-354. DOI: $10.1007 / B F 00711347$

Rogerson, C. M. (2011): From liquor to leisure: The changing South African hotel industry 1928-1968. Urban Forum, 22(4), str. 379-394. DOI: $10.1007 / \mathrm{s} 12132-011-9126-9$ 
Rogerson, C. M., in Rogerson, J. M. (2011): Tourism research within the Southern African development community: Production and consumption in academic journals, 2000-2010. Tourism Review International, 15(1-2), str. 213-224. DOI: 10.3727/154427211X13139345302487

Rogerson, C. M., in Visser, G. (ur.) (2004): Tourism and development issues in contemporary South Africa. Pretoria, Africa Institute of South Africa.

Rogerson, C. M., in Visser, G. (2006) :International tourist flows and urban tourism in South Africa. Urban Forum, 17(2), str. 199-213. DOI: $10.1007 / s 12132-006-0005-8$

Rogerson, C. M., in Visser, G. (ur.) (2007): Urban tourism in the developing world: The South African experience. New Brunswick, NJ, Transaction Press.

Rogerson, C. M., in Visser, G. (2011a): Rethinking South African urban tourism research. Tourism Review International, 15(1-2), str. 77-90. DOI: $10.3727 / 154427211 \times 13139345020336$

Rogerson, C. M., in Visser, G. (2011b): African tourism geographies: Existing paths and new directions. Tijdschrift voor Economische en Sociale Geografie, 102(3), str. 251-259. DOI: 10.1111/j.1467-9663.2011.00661.x

Rogerson, J. M. (2010): The boutique hotel industry in South Africa: Definition, scope and organization. Urban Forum, 21(4), str. 425-439. DOI: 10.1007/s12132-010-9104-7

Rogerson, J. M. (2011a): The changing all suite hotel in South Africa: From "extended stay" to African "condo hotel". Tourism Review International, 15(1-2), str. 107-121. DOI: 0.3727/154427211X13139345020417

Rogerson, J. M. (2011b): The limited services hotel in South Africa: The growth of City Lodge. Urban Forum, 22(4), str. 343-361.

DOI: $10.1007 /$ s12132-011-9130-0

Rogerson, J. M. (2012a): The changing location of hotels in South Africa's coastal cities. Urban Forum, 23(1), str. 73-91.

DOI: $10.1007 / \mathrm{s} 12132-012-9143-3$

Rogerson, J. M. (2012b): The South African hotel industry 1990 to 2010: Structure, segmentation and spatial change. Doktorska disertacija. Johannesburg, University of Johannesburg, Department of Geography, Environmental Management and Energy Studies.

Rogerson J. M. (2013a): Reconfiguring South Africa's hotel industry 1990-2010: Structure, segmentation and spatial transformation, Applied Geography, 36(1), str. 59-68. DOI: 10.1016/j.apgeog.2012.06.004

Rogerson J. M. (2013b): The economic geography of South Africa's hotel industry 1990-2010. Urban Forum, 24(3), str. 425-446. DOI: $10.1007 / s 12132-012-9186-5$

Rogerson, J. M., in Kotze, N. (2011): Market segmentation and the changing South African hotel industry 1990 to 2010. African Journal of Business Management, 5(35), str. 13523-13533.

Roper, A., in Carmouche, R. (1989): Budget hotels - A case of mistaken identity? International Journal of Contemporary Hospitality Management 1(1), str. 10-18. DOI: 10.1108/EUM0000000001664

Ruetz, D., in Marvel, M. (2011): Budget hotels: Low cost concepts in the U.S., Europe and Asia. V: Conrady, R., in Buck, M. (ur.): Trends and Issues in Global Tourism, str. 99-124. Berlin, Springer.

Rutes, W. A. Penner, R. H., in Adams, L. (2001): Hotel design: Planning and development. Oxford, Architectural Press.

Saunders, C., in Barben, T. (2007): The history of tourism. V: George, R. (ur.): Managing tourism in South Africa, str. 21-30. Cape Town, Oxford University Press.

Shoval, N., in Cohen-Hattab, K. (2001): Urban hotel development patterns in the face of political shifts. Annals of Tourism Research, 28(4), str. 908-925. DOI: 10.1016/\$0160-7383(00)00083-9
Smith, C., in Jenner, P. (1995): Hotels/accommodation: Hard budget hotels in France. Travel \& Tourism Analyst, 4(1), str. 53-65.

Solnet, D. J., Paulsen, N., in Cooper, C. (2010): Decline and turnaround: A literature review and proposed research agenda for the hotel sector. Current Issues in Tourism, 13(2), str. 139-159. DOI: $10.1080 / 13683500802638219$

Teng, F. (2010): Loyalty card promotional activity in budget hotel. Neobjavljena magistrska naloga. Karlstad, Karlstad University.

Teo, A. C. Y. (2001): How constitutive legitimation, sociopolitical legitimation, and competition affected foundings of Singapore hotels, 18321997. Journal of Hospitality and Tourism Research, 25(3), str. 302-319. DOI: $10.1177 / 109634800102500305$

Teo, P., in Chang, T. C. (2009): Singapore's postcolonial landscape: Boutique hotels as agents. V: Winter, T., Teo, P., in Chang, T. C. (ur.): Asia on tour: Exploring the rise of Asian tourism, str. 81-96. Abingdon, Routledge.

Timothy, D. J., in Teye, V. B. (2009): Tourism and the lodging sector. Oxford, Butterworth-Heinemann.

Tkaczynski, A., Rundle-Thiele, S. R., in Beaumont, N. (2007): Segmentation: A tourism stakeholder view. Brisbane, University of Southern Queensland.

TRI Hospitality Consulting (2007): Budget hotels 2007 UK. London.

Tsogo Sun Hotels Limited (2010): Annual report. Johannesburg.

Urtasun, A., in Gutiérrez, I. (2006): Hotel location in tourism cities: Madrid 1936-1998. Annals of Tourism Research, 33(2), str. 382-402. DOI: 10.1016/j.annals.2005.12.008

Visser, G. (2013): Looking beyond the urban poor in South Africa: The new terra incognita for urban geography? Canadian Journal of African Studies, 47(1), str. 75-93.

Wall, G., Dudycha, D., in Hutchinson, J. (1985): Point pattern analyses of accommodation in Toronto. Annals of Tourism Research, 12(4), str. 603618. DOI: 10.1016/0160-7383(85)90080-5 